\title{
Determination of Total Electron Content at Equatorial Region-Thailand Using Radio Occultation Technique*
}

\author{
Wasiu Akande Ahmed1,2, Ganiyu Ishola Agbaje ${ }^{2}$, Sikiru Yommy Aiyeola3 , Bola 0. Balogun², \\ Ngbede Joshua Ada Echoda², Yakubu Abdullahi Onimago², Taiwo Olunuga² \\ ${ }^{1}$ School of Instrumentation Science and Opto-Electronics Engineering, Beihang University of Aeronautics and \\ Astronautics, Beijing, China \\ ${ }^{2}$ African Regional Centre for Space Science and Technology Education-English, OAU Campus, Ile-Ife, Nigeria \\ ${ }^{3}$ School of Electronics and Information Engineering, Beihang University, Beijing, China \\ Email: wasto2007@gmail.com
}

Received 24 February 2016; accepted 26 April 2016; published 29 April 2016

Copyright (C) 2016 by authors and Scientific Research Publishing Inc.

This work is licensed under the Creative Commons Attribution International License (CC BY). http://creativecommons.org/licenses/by/4.0/

(c) (i) Open Access

\section{Abstract}

This paper investigates the total electron content (TEC) which is a major challenge to space and related industries, most especially in an equatorial region like Thailand within the geographical latitude $07^{\circ} 35^{\prime} \mathrm{N}-20^{\circ} 17^{\prime} \mathrm{N}$. This research was achieved using radio occultation data from COSMIC mission. The monthly, seasonal and annual TEC and electron density variation monitoring conducted during increasing solar activity from 2010 to 2013 due to changes and instability of ionospheric parameters. It was observed that electron density and TEC was predominant in summer season. Summer has the highest electron density and TEC values all through and the annual mean values keep on increasing within the period under consideration. In conclusion, ionospheric fluctuations and perturbations were observed to be at pick between the months of March and May. The results of the study demonstrated that ionospheric irregularities were steadily on the increase, confirming 24th solar cycle prediction by NASA and depended on many factors among the major ones which are located on the latitude, season and solar activity.

\section{Keywords}

TEC, Ionosphere, GPS, Low Earth Orbit, Radio Occultation, Equatorial Zone

\footnotetext{
*Ionospheric communication delay measurement due to total electron content (TEC).
} 


\section{Introduction}

Ionosphere is the upper layer of the Earth atmosphere which has a great impact on signal from telecommunication system. It consists of free electrons and ions that are mostly concentrated in the F-region and produced mainly by solar radiation [1]. It causes delay of electromagnetic signals passing through it being a dispersive medium [2]. Ionosphere influences GPS signals mostly in the equatorial region within latitude of $20^{\circ} \mathrm{N}$ and $20^{\circ} \mathrm{S}$ which results in error measurements and hence, the need to analyze the variation of the total electron content in the ionosphere. Radio occultation data processing system (see Figure 1(a)) in essence was developed for the purpose of numerical weather prediction and climate benchmarking [3]. Right from the pioneer GPS/MET mission, low earth orbit (LEO) based GNSS radio occultation (RO) technique has been a powerful technique in ionosphere monitoring. Subsequently, many LEO satellites were launched with radio occultation payload, which included: CHAMP, GRACE, SACC/D, COSMIC, C/NOFS, Metop-A/B, and TerraSAR-X/TanDEM-X [4] [5].

The fundamental problem addressed in this paper although very difficult is the ionospheric electron density and TEC fluctuations monitoring. Determining the amount of free electrons present within the ionospere over Thailand was carried out and then integrated to obtain total electron content. It shows to be more violent during the summer for the period of four years. This study is vital to space applications related organizations such as aviation, military and space weather, for numerical weather prediction and security purposes. The paper outline is as follows: Section 2 presents the data description and methodology. Section 3 analyzes the results and finally Section 4 is the conclusion.

\section{Data Description and Methodology}

\subsection{Data Description}

The Global Positioning System Ionospheric Radio Occultations are obtained from the COSMIC Data Analysis and Archive Centre (CDAAC) website. The ionospheric level 12 operational data products are made available within 24 hours by UCAR/CDAAC. The data products output used in this paper are ionospheric profiles of electron density (ionprf) whose accuracy is generally about $10^{4}-10^{5} \mathrm{~cm}^{-3}$ and in NetCDF format. Observation shows that, cycle slips may affect some of these profiles [6]. UCAR/CDAAC is the only primary data processing centre particularly dedicated for COSMIC mission. This data is made available to the public both ftp and http server through CDAAC. One of the most important radio occultation products is the electron density profile for ionosphere. It is achieved from the calculation of excess phase file for each occultation with the aid of Abel inversion.

\subsection{Methodology}

COSMIC satellite is provided with four antennas each with which ionospheric electron density measurements is taken. Two antennas are used one for rising and one for setting occultation during this period. The GPS satellite receiver onboard LEO can track up to 13 GPS satellites through the two antennas and measure the difference GPS phase data on L1 and L2 every second. The bend angle, $\alpha$ (of the satellite or radio signals) obtained through

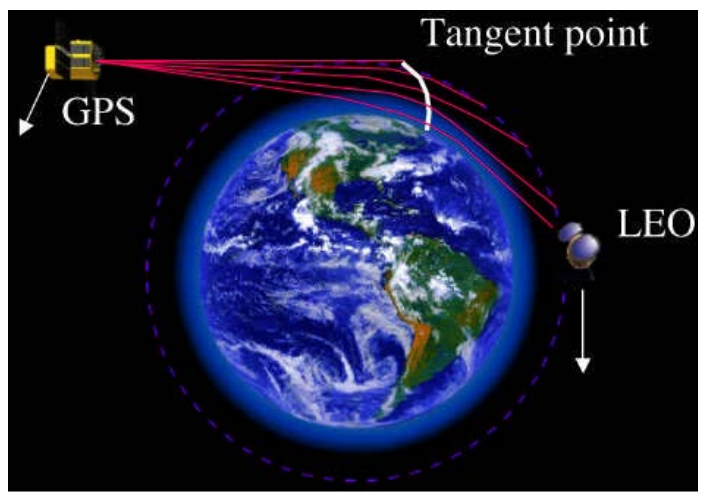

(a)

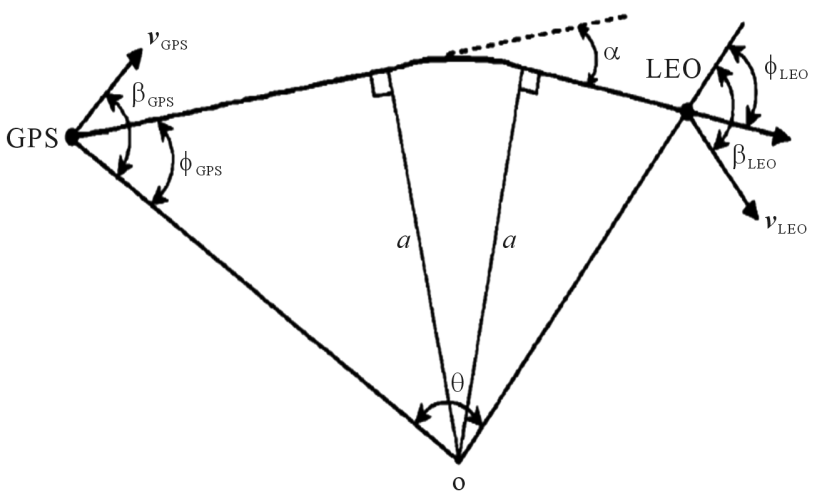

(b)

Figure 1. Schematic diagram illustrating radio occultation, geometric of ray, bending angle $\alpha$ and impact parameter $a$ [10]. 
Abel inversion method is used to compute the refractivity. The radio occultation electron density profile retrieval approach is based on a few assumptions and approximations such as straight line signal propagation, coplanar of GNSS ray, spherical symmetry of electron density, circular LEO orbit and first order estimation of orbital electron density. Even though radio occultation technique is characterized with high precision, provides global profiles and maps of the atmospheric boundary layer, no satellite to satellite bias, self calibration, independent of processing centre, the spherical symmetry assumptions used in Abel inversion is known to be the most significant source of error [7] [8]. TEC calculation involves the integration of electron density along the straight line (signal path) between the LEO receiver and GPS transmitter (as demonstrated in Equation (11)). Measuring the phase delay of radio waves at L1 and L2 frequencies from GPS as they are occulted by the earth atmosphere is illustrated in Figure 1(a) and note that the sample rate per second is $1 \mathrm{~Hz}$. The simulated STEC (Slant TEC) is then inverted into electron density profile along the tangent points by the same Abel inversion software (Bernese v5.0 software package) used for CDAAC electron density profiles retrieval [9].

\section{Ionospheric Bending and Refractivity}

The refractivity of the radio signals passing through the ionosphere depends majorly on the amount of electron density and ions, time of the day and carrier frequency. It is expressed as shown in Equation (1) in which the refractive index is proportional to the electron density and inversely proportional to the square of the carrier frequency:

$$
n^{2}-1=-80.6 \times 10^{6} \mathrm{~N} / \mathrm{f}^{2}
$$

where the index of refraction is denoted with $n^{2}, N$ is the electron density $\left(\mathrm{el} \mathrm{cm}^{-3}\right)$ and $f$ is the signal frequency (Hz).

As mentioned earlier; the constraint problem when constructing a 3-D refractivity field from 1-D observational data is the assumption; spherical symmetry of refractivity around the extended region of the perigees of the sounding rays. The Snell's law is obtained when the 3-D ray equations are integrated under this assumption. Therefore, the bending angle $\alpha$ and excess phase $s$ are given as follows:

$$
\begin{gathered}
\alpha(a)=-a\left[\int_{a}^{x \mathrm{KGS}}+\int_{a}^{x L \mathrm{EO}}\right] \frac{\mathrm{d} n / \mathrm{d} x}{n(x) \sqrt{x^{2}-a^{2}}} \mathrm{~d} x \\
S(a)=\left[\int_{a}^{x \mathrm{KPS}}+\int_{a}^{x \mathrm{LEO}}\right] \frac{x\left(1-x n^{-1} \mathrm{~d} n / \mathrm{d} x\right)}{\sqrt{x^{2}-a^{2}}} \mathrm{~d} x-L_{G L}
\end{gathered}
$$

where $a$ is defined as the impact parameter ( $a=\rho n(\rho)$ ), $\rho$ is the distance from the ray tangent point to the centre of sphericity of the refractivity field, $x=r n(r)$ represent the fractional radius ( $r$ is radius) and $L_{G L}$ denotes the distance between the GPS and LEO satellites. Figure 1(b) shows the bending angle $\alpha$ and impact parameter $a$ that are used in Equations (2) and (3) as well as the ray geometry.

Ionospheric refractivity is negligible at GPS orbit altitudes in the first term of Equation (2) while the second term (LEO) is not. The bending angle does not depend on the positions of the GPS and LEO satellite, excess phase and ray separation from a straight line connecting the satellites. Calculations based on Figure 1(b) were done by numerical integration of Equations (2) and (3) where $L_{1}$ frequency $\left(f=f_{1}\right)$ and $L_{2}\left(f=f_{2}\right)$.

\subsection{Theory of Abel Inversion and Techniques}

\section{Abel Inversions}

In this section under the assumption of spherical symmetry, the formulations for the construction of electron density profile through the use of bending angle data and excess phase (TEC) data was conducted.

\section{1) Abel Inversion Obtained from Bending Angle Data}

To determine the bending angle from excess phase, the relationship between Doppler shift of the carrier frequency, $f_{d}=-f c^{-1}(\mathrm{~d} S / \mathrm{d} t)$ and the projections of satellite velocities at the GPS and LEO positions is as follows:

$$
f_{d}=f\left[\frac{c-n_{\mathrm{LEO}} v_{\mathrm{LEO}} \cos \left(\beta_{\mathrm{LEO}}-\phi_{\mathrm{LEO}}\right)}{c-n_{\mathrm{GPS}} v_{\mathrm{GPS}} \cos \left(\beta_{\mathrm{GPS}}-\phi_{\mathrm{GPS}}\right)}-1\right]
$$


For $\tilde{v}_{\mathrm{GPS}}$ and $\tilde{v}_{\mathrm{LEO}}$ represent 2-D projections of GPS and LEO satellite 3-D velocities respectively on the occultation plane, $c$ is defined as the velocity of light in a vacuum, angles $\beta$ and $\phi$ are defined in Figure 1(b) while $n_{\mathrm{LEO}}$ and $n_{\mathrm{GPS}}$ denotes the indices of refraction. It is observed that Equation (4) has insufficient information to solve for $\phi_{\mathrm{GPS}}$ and $\phi_{\mathrm{LEO}}$ as it contain only Doppler data. Based on the assumption made, Snell's law is incorporated as shown below to complement Equation (4):

$$
r_{\mathrm{GPS}} n_{\mathrm{GPS}} \sin \phi_{\mathrm{GPS}}=r_{\mathrm{LEO}} n_{\mathrm{LEO}} \sin \phi_{\mathrm{LEO}}=a
$$

Solving both Equations (4) and (5) iteratively to obtain the impact parameter, $a$ and the bending angle, $\alpha$ with the aid of Equation (6):

$$
\alpha=\phi_{\mathrm{GPS}}+\phi_{\mathrm{LEO}}+\theta-\pi
$$

Solving Equations (4) and (5) causes an error due to the assumption of the refractivity at GPS and LEO positions to be unity.

\section{2) Abel Inversion Obtained from Total Electron Content Data}

Total electron content is a measure of propagation delay time of the radio signal transmitted from the satellite to the receiver. The total electron content (TEC), $T$ along the signal path can be related to electron density $N$, excess phase $S$ and index of refraction $n$ as:

$$
T=\int N \mathrm{~d} l=-\frac{f^{2}}{40.3 \times 10^{6}} \int(n-1) \mathrm{d} l=-\frac{f^{2} S}{40.3}
$$

$S$ is measured in metres (m) and $T$ in (TEC (0.1 TECu).

If bending is neglected, TEC can be obtained from $S_{1}-S_{2}\left(L_{1}-L_{2}\right)$ as shown in Equation (8):

$$
T=-\frac{\left(S_{1}-S_{2}\right) f_{1}^{2} f_{2}^{2}}{40.3\left(f_{1}^{2}-f_{2}^{2}\right)}
$$

It is advantageous using $\left(S_{1}-S_{2}\right)$ or $\left(L_{1}-L_{2}\right)$ to estimate TEC as it automatically eliminate the orbit and clock errors from the difference while the disadvantage is that when anti-spoofing is activated $L_{2}$ noise is introduced which may degrade the TEC inversion results [10] [11]. Just like the inversions through bending angles using the assumption of spherical symmetry, it is thus adopted in electron density for TEC inversions. Then, TEC in Equation (8) is related to electron density as shown in Equation (9):

$$
T\left(r_{0}\right)=\left[\int_{r_{0}}^{r_{\mathrm{GPS}}}+\int_{r_{0}}^{r_{\mathrm{LEO}}}\right] \frac{r N(r)}{\sqrt{r^{2}-r_{0}^{2}}} \mathrm{~d} r
$$

$r_{0}$ is defined as the impact distance of the straight line connecting the GPS and LEO satellites. Hence, TEC data calibration is done along the ray path as demonstrated in Figure 2 and expressed as in Equation (10):

$$
\tilde{T}\left(r_{0}\right)=T_{H I}\left(r_{0}\right)=T_{G I}\left(r_{0}\right)-T_{G H}\left(r_{0}\right)
$$

The calculation of $r_{0}$ (the straight line impact distances) is carried out for all observational data with respect to the point where there is maximum impact distance. Then, the interpolation of uncalibrated TEC as a function of impact distance with the aids of cubic splines. Calibration of TEC is the next stage, i.e. $\tilde{T}\left(r_{0}\right)$. Now, the calibrated TEC Equation (10) becomes:

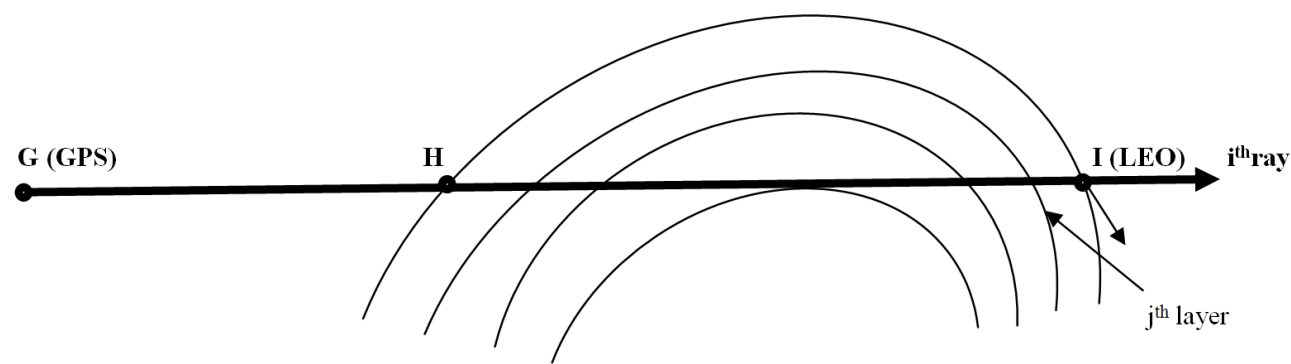

Figure 2. Total electron content and bending angle calibration geometry diagrammatic illustration. 


$$
\tilde{T}\left(r_{0}\right)=2 \int_{r_{0}}^{r_{\text {LEO }}} \frac{r N(r)}{\sqrt{r^{2}-r_{0}^{2}}} \mathrm{~d} r
$$

Equation (11) can be further expressed in terms of $N(r)$ as:

$$
N(r)=-\frac{1}{\pi} \int_{r}^{r_{\mathrm{LEO}}} \frac{\mathrm{d} \bar{T} / \mathrm{d} r_{0}}{\sqrt{r_{0}^{2}-r}} \mathrm{~d} r_{0}
$$

\section{Results and Discussions}

\subsection{Variability of the Ionospheric Monthly TEC and Electron Density}

Monthly TEC and electron density variation analysis are highly recommended and of great importance in the investigation of electron density and TEC since ionospheric irregularities are natural phenomena and contribute to a large extent ionospheric communication outages of radio signals. The only way to minimize its effect is to monitor the electron density and total electron content (TEC) though a very difficult task in real-time as it is constantly changing over time and space. The intensity and effects of the sun activity varies from month to month and even the hours of solar activity are not the same. The study was carried out during the increasing solar activity according to 24th solar cycle prediction by National Aeronautics and Space Administration as shown in Figure 3.

COSMIC radio occultation technique was used to retrieve electron density profile (TEC) data in Thailand from 2010 to 2013 to extract the monthly mean TEC and mean electron density as shown in Figure 4 and Figure 5 respectively.

There were periodical characteristic in the inter-monthly variation of the TEC and electron density in Thailand. It can be observed in 2010 that the mean peak TEC value was 140 (TECu) in April while the months of May, September and October were high above 100 (TECu). 2011 showed a higher mean peak TEC value of 260 (TEC) in the month of December while the Months of April, May, September and October was a bit higher than in 2010. It can be deduced from monthly TEC variation analysis in 2012 and 2013 that, the mean peak TEC value further increased to 275 (TECu) and 375 (TECu) respectively in the month of April and May. Although there was data loss during the months of February, September, October, November and December in 2013 which could be due to system failure (hardware or software problem). A critical look and comparison of Figure 4 and Figure 5 shows electron density is proportional to total electron content.

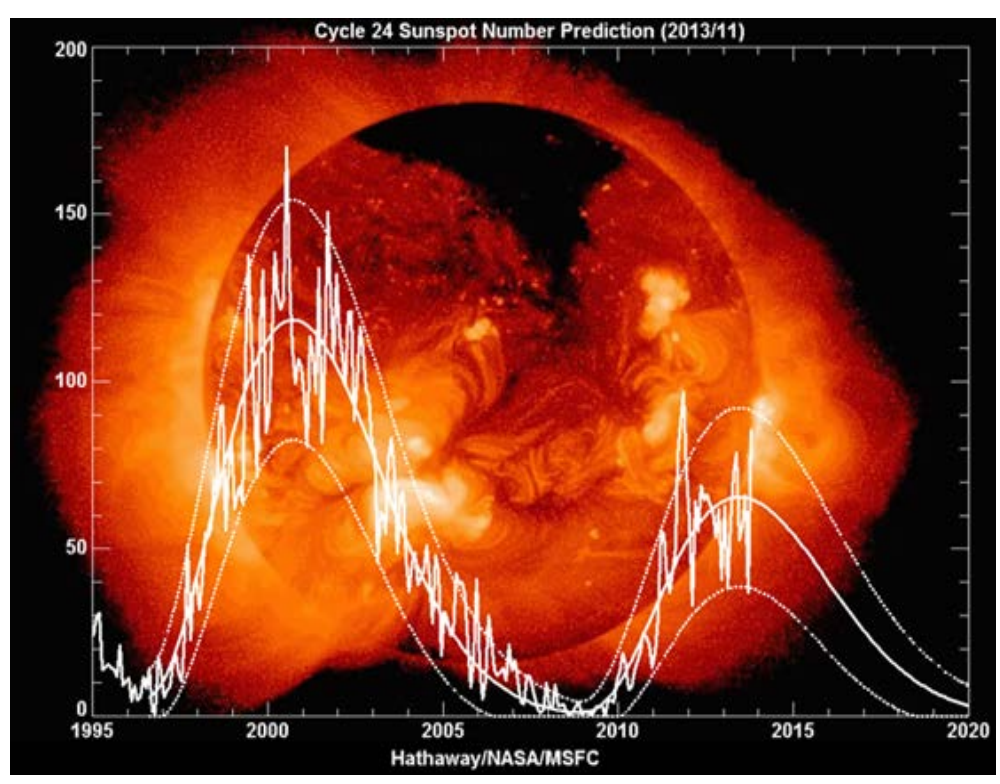

Figure 3. National aeronautics and space administration 24th solar cycle prediction [12]. 

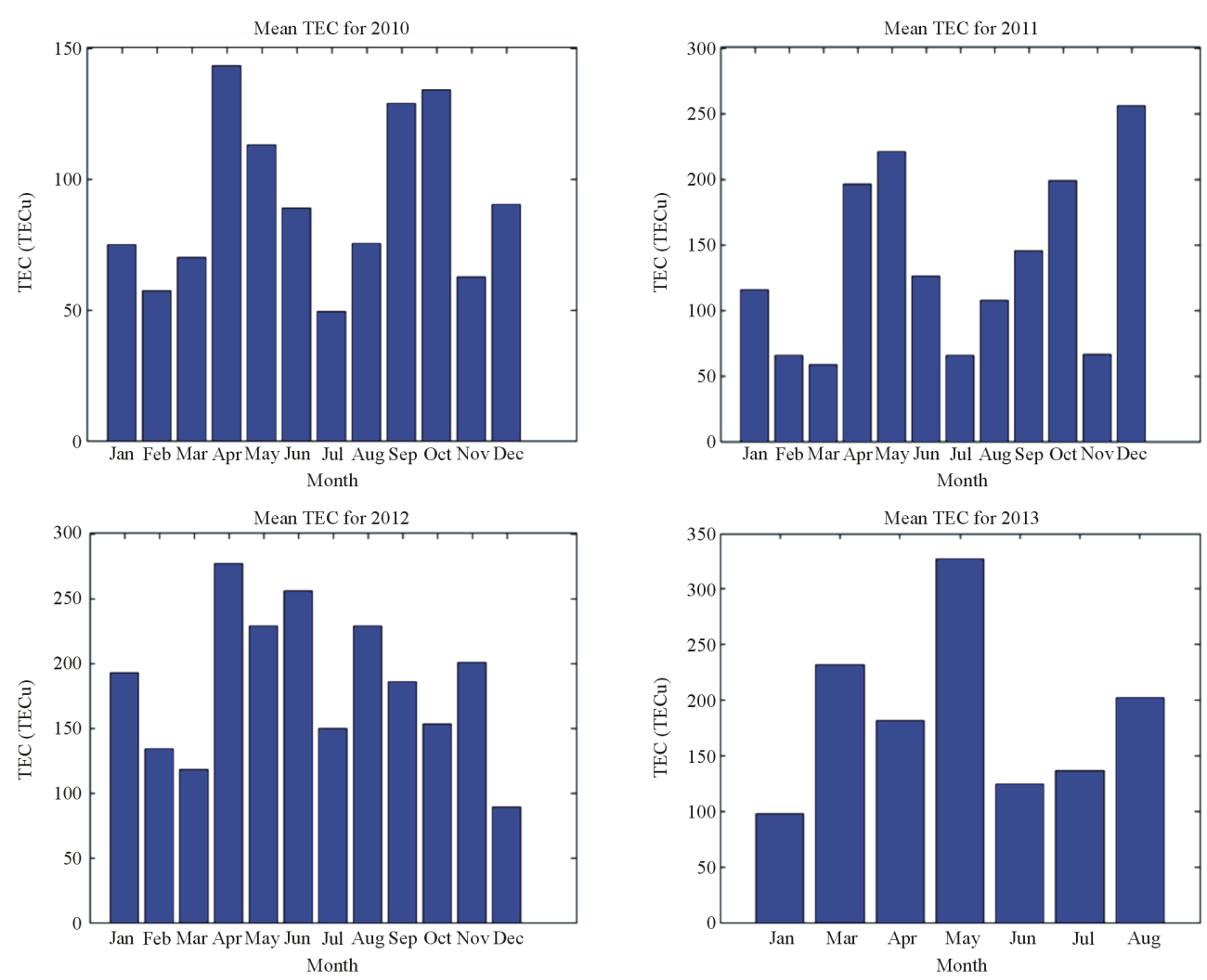

Figure 4. Variability of the monthly total electron content.
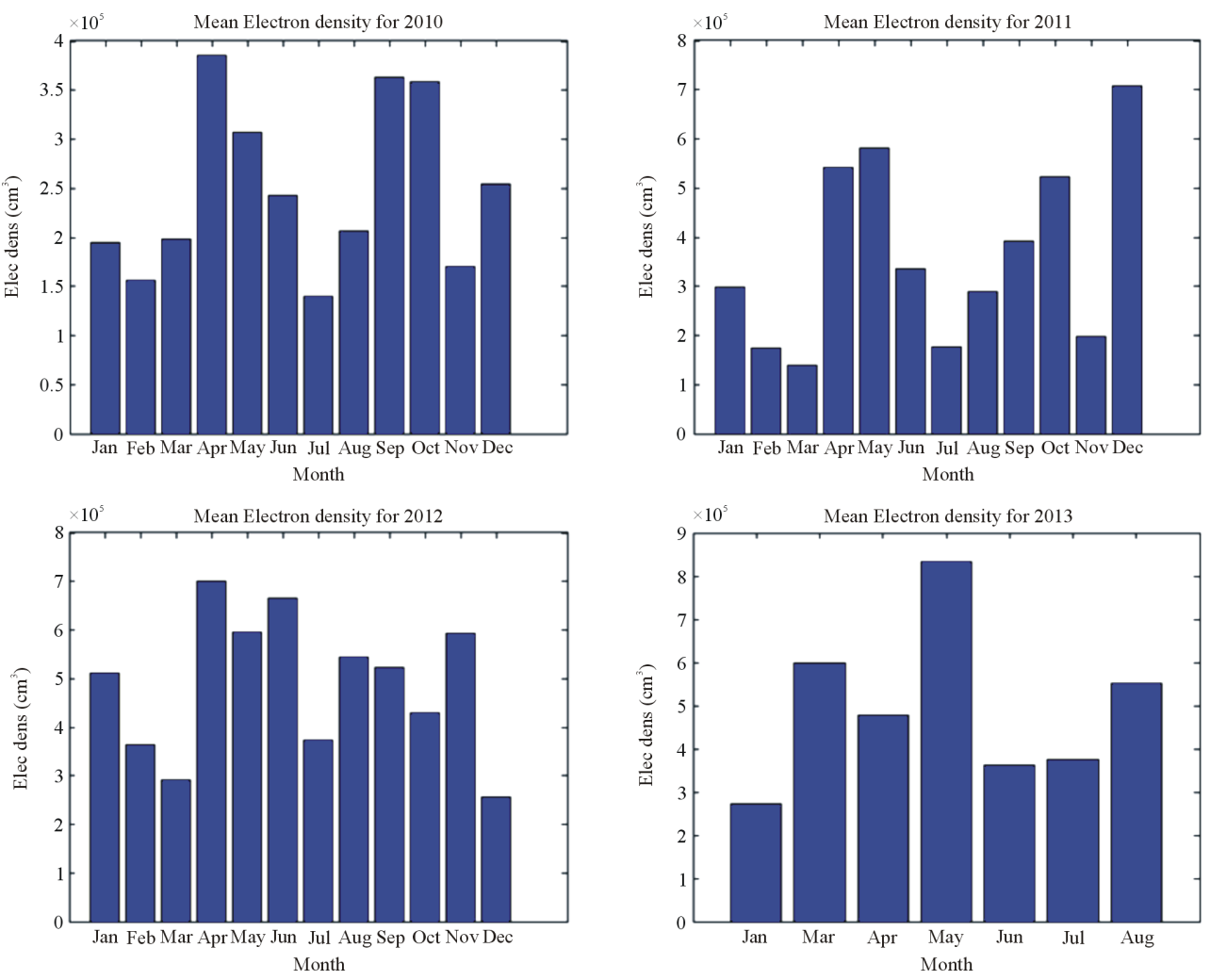

Figure 5. Variability of monthly electron density. 
Generally, from 2010 to 2013, there was consistence and drastic increment in the values of TEC and electron density. Take for instance, the mean peak TEC and mean Peak electron density values increased from 140 (TE$\mathrm{Cu})$ to 375 (TECu) and $3.8 \times 10^{5} \mathrm{~cm}^{3}$ to $8.2 \times 10^{5} \mathrm{~cm}^{3}$ respectively. It means that the monthly mean TEC and electron density characteristics correlate with 24th solar cycle prediction by National Aeronautics and Space Administration in which the solar activity was on the increase within the period of this investigation [13]. Except in 2011, it was also clear that the months that made up summer season were observed to be very high.

\subsection{Seasonal Variability of Ionospheric TEC and Electron Density Monitoring}

Since seasonal variation plays a vital role in electron density and TEC variation, it is thus pertinent in this research to carry out seasonal ionospheric analysis to investigate the increasing solar activity and TEC behaviour during this period. In this paper, there are three distinct seasons which are winter, summer and rainy in Thailand. Winter comprises November, December, January and February. The summer is made up of March, April, and May while rainy season consists of June, July, August September and October. For each season, the mean TEC and electron density values were determined and characteristics displayed.

TEC and electron density values changed dynamically from one season to the other and the observation made in the course of this research was that the ionospheric mean TEC and electron density was at peak during the summer period and the least ionospheric mean TEC and electron density was experienced during the winter season throughout the period of this investigation as displayed in Figure 6 and Figure 7 respectively. These results are in conformity with theoretical background that the impacts of solar activity on the earth's atmosphere must be taken into account [13]. In summer solar activities was significantly high while during the winter the energy released by the sun was very low. Therefore, there was high concentration of free electrons interfering with the radio signal in summer than in winter. Other paper that gave similar results includes [14].

Based on the results obtained, the seasonal mean TEC and electron density increased from 2010 to 2013 except for winter and rainy seasons that declined in 2013 which may be due to data loss, cycle slips or multipath. Following the trend generally, there was increment in the TEC and electron density characteristics and that means it complied with NASA solar cycle prediction curve.
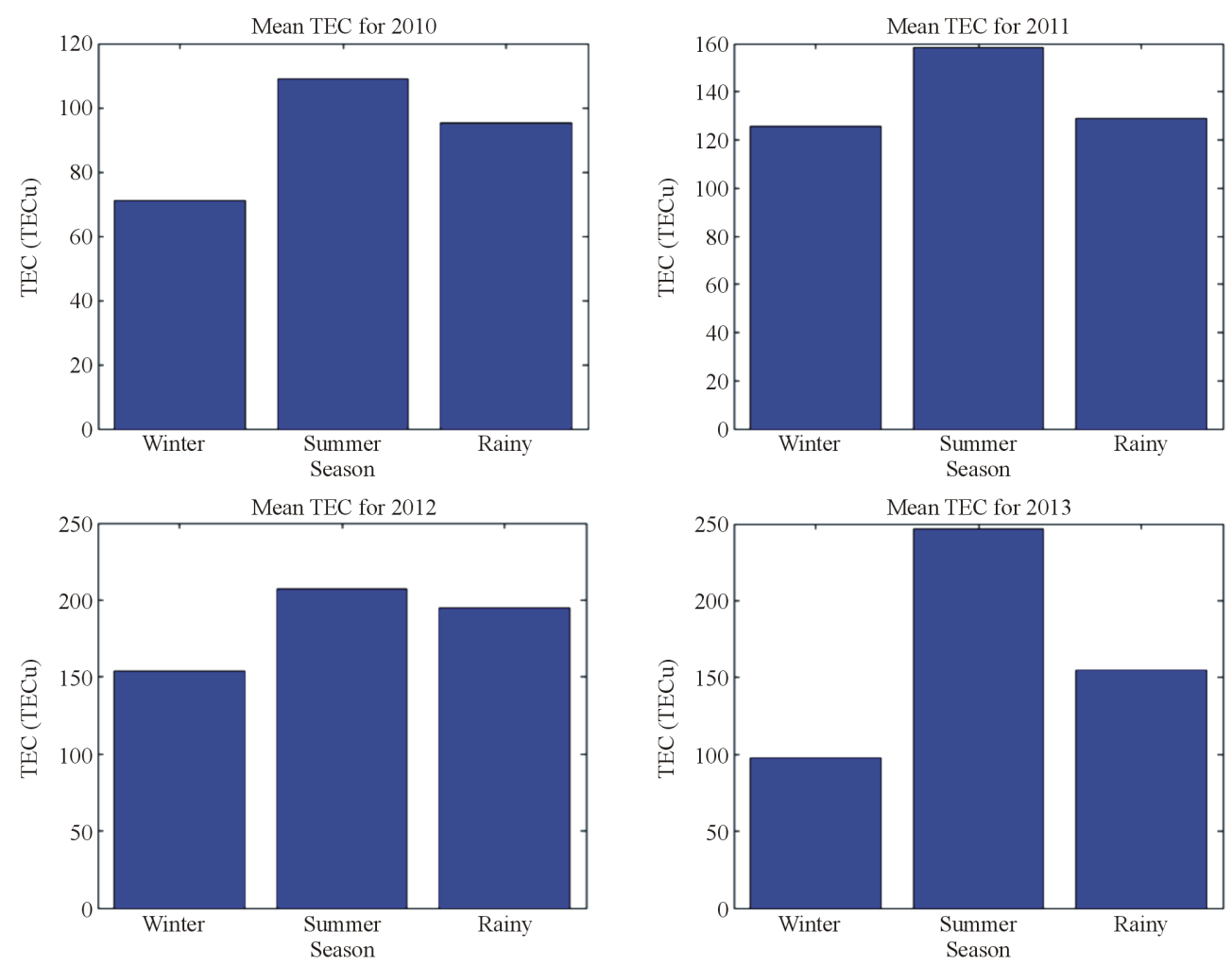

Figure 6. Seasonal variation of ionospheric total electron content. 


\subsection{Annual Ionospheric TEC and Electron Density Monitoring}

Solar activity differs annually as clearly predicted by NASA curve and therefore required to be studied in order to monitor and determine why there are annual variations in electron density and TEC. Annual TEC and electron density variations from year 2010 to 2013 are shown in Figure 8. The trend shows the mean annual TEC and electron density kept steadily increasing. It means that characteristic of electron density and TEC variations were influenced by solar activity monthly, seasonally and annually. The monitoring of electron density and TEC characteristics as seen helps space application industries in their planning and gives awareness of the kind of the problem they are likely to face at a particular time and enable them proffer solution to it. Therefore, the signal degradation and interference was on the increase from 2010 to 2013.
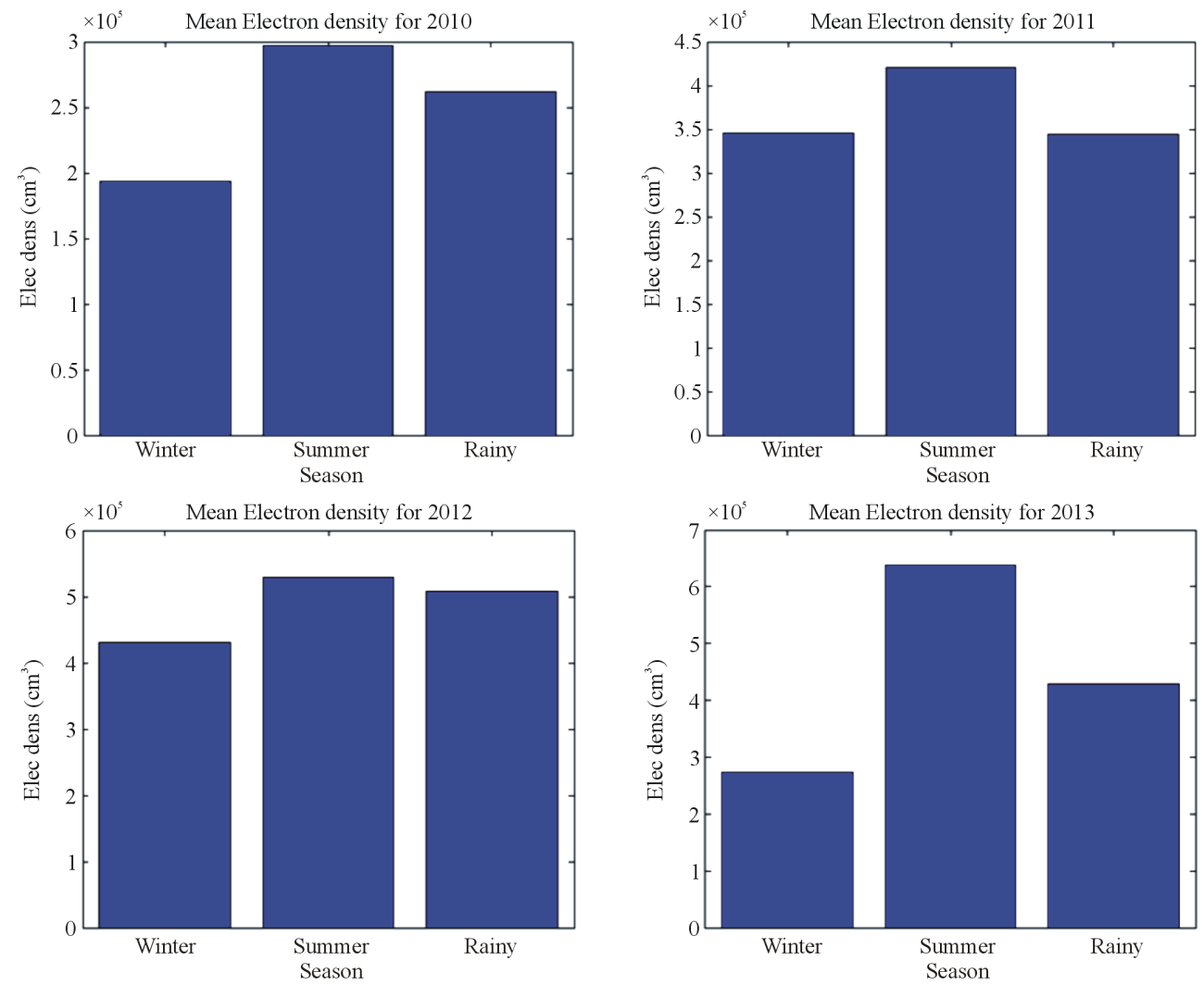

Figure 7. Seasonal variation of ionospheric electron density.
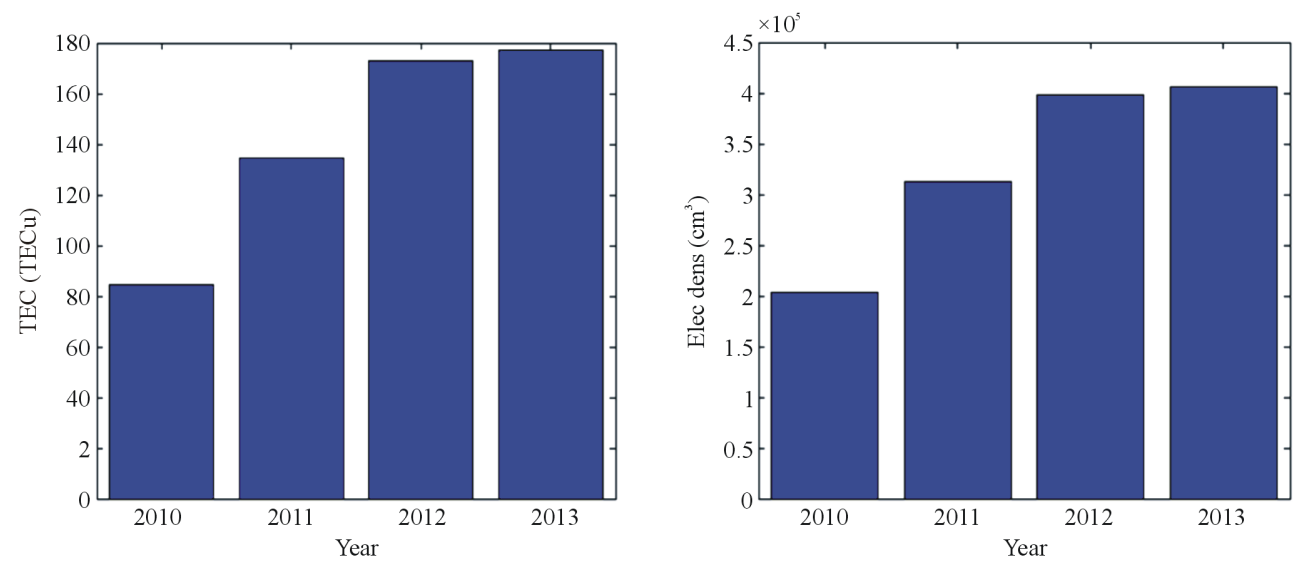

Figure 8. Annual electron density and total electron content variation monitoring. 


\section{Conclusions}

This research work has investigated the dynamic behaviours of ionospheric electron density and TEC within Thailand geographical region. Ionospheric electron density and TEC variations were monitored monthly, through the seasons and on annual basis from 2010 to 2013. This research was conducted to monitor the instability of solar activity and also to guide against serious adverse effects of electron density concentration and TEC from time to time. The results showed an increasing trend of ionospheric electron density and TEC values except in 2013 when the values declined for the rainy and winter seasons. It could be as a result of data loss, cycle slips and possibly multipath within the period. It was obviously established that electron density was proportional to total electron.

Based on the results and observations, it is therefore concluded that telecommunications, geodetic and navigation systems will experience more error during summer (strong solar activity). Thus, users of GPS applications such as security agencies, military and aviation industries in Thailand may take the advantage of this clue to avoid the period of atmospheric disturbance and error.

\section{Acknowledgements}

The authors express their sincere thanks and gratitude to University Corporation for Atmospheric Research (UCAR) Constellation Observing System for Meteorology, Ionosphere, and Climate (COSMIC) Program Office for their support and permission to freely use data from their website. Also profound gratitude goes to the management of African Regional Centre for Space Science and Technology Education in English, Ile-Ife, Nigeria for the great opportunity given to be a part of 2014 GNSS Space Application Training in Beihang University, China.

\section{References}

[1] Norsuzila, Y., Mardina, A. and Mahamud, I. (2008) Determination of GPS Total Electron Content Using Single Layer Model (SLM) Ionospheric Mapping Function. International Journal of Computer Science and Network Security, 8, 154-160.

[2] Bolaji, O.S., Izang, P.A., Oladosu, O.R., Koya, F., Fayose, R.S. and Rabiu, A.B. (2015) Ionospheric Time-Delay over Akure Using Global Positioning System Observations. Institute of Geophysics, Polish Academy of Sciences, 63, 884899. http://dx.doi.org/10.1515/acgeo-2015-0018

[3] Wickert, J., Arras, C., Ao, C.O., Beyerle, G., Falck, C., Grunwaldt, L., Healy, S.B., Heise, S., Helm, A., Huang, C.Y., Jakowski, N., König, R., Mannucci, T., Mayer, C., Michalak, G., Poli, P., Rothacher, M., Schmidt, T., Stosius, R. and Tapley, B. (2008) CHAMP, GRACE, SAC-C, TerraSAR-X/TanDEM-X: Science Results, Status and Future Prospects. GRAS SAF Workshop on Applications of GPSRO Measurements, 16-18 June 2008, 43-52.

[4] Anthes, R.A. (2011) Exploring Earth’s Atmosphere with Radio Occultation: Contributions to Weather, Climate and Space Weather. Atmospheric Measurement Techniques, 4, 1077-1103. http://dx.doi.org/10.5194/amt-4-1077-2011

[5] Biondi, R., Neubert, T., Syndergaard, S. and Nielsen, J.K. (2011) Radio Occultation Bending Angle Anomalies during Tropical Cyclones. Atmospheric Measurement Techniques, 4, 1053-1060. http://dx.doi.org/10.5194/amt-4-1053-2011

[6] CDAAC (2015) COSMIC Data Analysis and Archive Center-Data Products. http://cdaac-www.cosmic.ucar.edu/cdaac/products.html

[7] Yue, X., Schreiner, W.S., Lei, J., Sokolovskiy, S.V., Rocken, C., Hunt, D.C. and Kuo, Y.H. (2010) Error Analysis of Abel Retrieved Electron Density Profiles from RO Experiments. Annales Geophysicae, 28, 217-222. http://dx.doi.org/10.5194/angeo-28-217-2010

[8] Wickert, J. (2013) Space Based GNSS Atmosphere Sounding: Radio Occultation. GfG² Summer School, GFZ Potsdam.

[9] Guo, P., Wu, M.J., Xu, T.L., Jin, H.L. and Hu, X.G. (2015) An Abel Inversion Method Assisted by Background Model for GPS Ionospheric Radio Occultation Data. Journal of Atmospheric and Solar-Terrestrial Physics, 123, 71-81. http://dx.doi.org/10.1016/j.jastp.2014.12.008

[10] Schreiner, W.S., Sokolovskiy, S.V., Rocken, C. and Hunt, D.C. (1999) Analysis and Validation of GPS/MET Radio Occultation Data in the Ionosphere. Radio Science, 34, 949-966. http://dx.doi.org/10.1029/1999RS900034

[11] Lei, J., Syndergaard, S., Burns, A.G., Solomon, S.C., Wang, W., Zeng, Z. and Lin, C.H. (2007) Comparison of COSMIC Ionospheric Measurements with Ground-Based Observations and model Predictions. Preliminary Results. Journal of Geophysical Research, 112, A07308. http://dx.doi.org/10.1029/2006JA012240 
[12] Cycle 24 Sunspot Number Prediction (2016/01) 300 ... -NASA. http://solarscience.msfc.nasa.gov/images/ssn_predict.pdf

[13] Kornyanat, W., Pornchai, S., Somkiat, L., Takuya, T., Tsutomu, N. and Takashi, M. (2012) TEC Prediction with Neural Network for Equatorial Latitude Station in Thailand. Earth Planets Space, 64, 473-483. http://dx.doi.org/10.5047/eps.2011.05.025

[14] Ahmed, W.A., Wu, F., Oladosu, R.O., Phunthirawuthi, P., Echoda, N.J.A., Onimago, A.Y. and Olunuga, T. (2015) Ionospheric Behaviour Analysis over Thailand Using Radio Occultation Technique. International Journal of Engineering Research and Applications, 5, 1-7. 